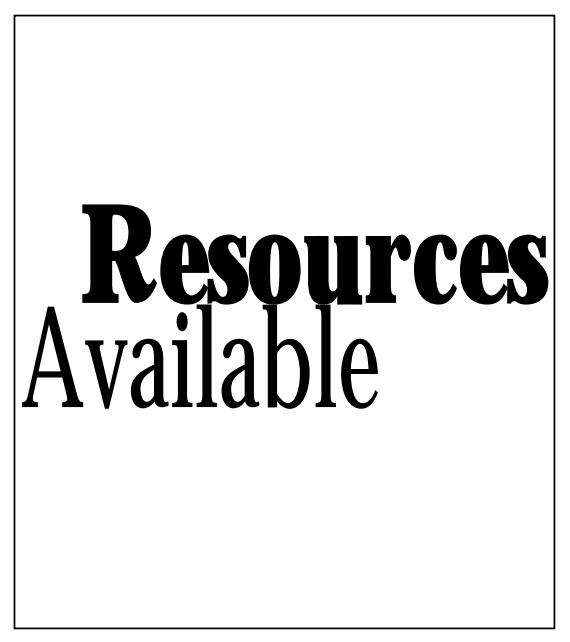

\section{Common Tree Fruit Pests}

A ngus $\mathrm{H}$. H owitt, M ichigan State U niv., NCR. This is a $\mathrm{N}$ orth Central Regional Extension publication available from the PublicationsOffice, CooperativeExtension Service, Michigan State U niv., East Lansing, MI 48824-1039. \$37.50 for hardcover and $\$ 30.00$ for paperback.

This book is the compilation of notes gathered by the author working as a fruit entomologist and teaching an off-campus course in fruit ento- mology. It is intended for the fruit researcher, professional consultant, extension specialist, commercial grower, and serious hobbyist.

The book is a series of fact sheets discussing more than 50 arthropod pests of pome and stone fruits. Color photographs are presented for easy field identification, and the text discusseseach pest'slifestages, host range, injury or damage, factors affecting abundance, life history, monitoring, and control. Pests are group by commodity and by their feeding or damage behavior. Charts showing typical emergence patterns in $M$ ichigan are provided for a majority of the pests. These graphs nicely compliment the basic biological data found in the text. D egree-day calculations for specific emergence events also are presented in the text, so that pest emergence may be predicted by readerslocated in other regions of the country.

There is a classic introductory chapter on the basic facts of insect and mite biology and concluding chapters on integrated pest management and beneficial arthropods. A glossary also is provided for entomological and horticultural terms for readers who may not be familiar with the technological terminology. This is a nice addition.
There are very few weaknesses in this book, but monitoring methods for some pests are a bit out-dated. That is not to say that the monitoring methods presented are not still useful, but sampling technology hasimproved over the past several years for a number of key pests of apples, particularly apple maggot, European red mite, leafrollers, and leaf miners. The book lacks sections on a few pests from other northern fruit-growing regions, and the beneficial section does not mention the major mite predator in the northern U nited States, Typhlodromus pyri. H owever, this book will serve as a good diagnostic tool for a majority of the arthropod pest situations that may beencountered in most fruit orchards in the U nited States.

In conclusion, this book is an excellent resource for tree fruit pests and a valuablefield identification tool. I highly recommend it to anyone interested in orchard pest management systems

J oseph K ovach I PM Program Cornell U niv.

$\mathrm{N}$ ew Y ork State A gr. Expt. Sta. Geneva, NY 14456 